\title{
Juventude latino-americana e mercado de trabalho: programas de capacitação e inserção
}

\author{
Aline Espindola Dornelles \\ Fundação de Assistência Social e Cidadania - Prefeitura Municipal \\ de Porto Alegre \\ Carlos Nelson dos Reis \\ Pontifícia Universidade Católica do Rio Grande do Sul (PUCRS)
}

\author{
Vanessa Maria Panozzo \\ Universidade Federal do Rio Grande do Sul (UFRGS)
}

Juventude latino-americana e mercado de trabalho: programas de capacitação e inserção

Resumo: O presente artigo sintetiza os resultados da pesquisa que analisou o conteúdo dos programas sociais vigentes na América Latina como uma das respostas construídas para as Metas de Desenvolvimento do Milênio. A pesquisa quantitativa e qualitativa observou especificamente os programas sociais de capacitação e inserção vigentes para a juventude nos países da Região, mapeando as experiências e explicitando suas características a partir de 1990. A pesquisa indica a caracterização da inserção do jovem em trabalhos informais, sem proteção social, com aumento nas taxas de desemprego e sem nenhuma estabilidade no trabalho. Nesses países há um número significativo de propostas privadas em parceria com a sociedade civil, ao invés de um investimento qualificado na consolidação de estruturas para a população jovem.

Palavras-chave: Juventude. Mercado de Trabalho. América Latina.

Latin American Youth and the Labor Market: Training programs and insertion

Abstract: This article synthesizes the results of a study that analyzed the content of current social programs in Latin America as some of the responses constructed to respond to the Millennium Development Goals. The quantitative and qualitative study specifically observed social programs for training and insertion of youth in countries in the region, mapping the experiences and presenting their characteristics since 1990. The study found the insertion of youth in informal work, without social protection, and an increase in unemployment rates and a lack of employment stability. In these countries, there is a significant number of private programs in partnership with civil society, instead of a qualified investment in the consolidation of structures for the youth population.

Keywords: Youth. Labor Market. Latin America. 


\section{Introdução}

No caminho que vem percorrendo, a sociedade latino-americana, em especial a juventude no século 21, traz em sua bagagem um histórico de grandes transformações econômicas, políticas e sociais que repercutem diretamente no cotidiano dos jovens inseridos ou não no mercado de trabalho, ou em programas voltados à capacitação para sua inserção. As consequências das reformas estruturais e da introdução de políticas de estabilização, principalmente nos anos 1990, impuseram a América Latina a necessidade de introduzir novas políticas para a juventude, resultando na formatação de novos recortes de programas voltados à capacitação e à inserção do jovem no mercado de trabalho.

Este artigo é resultado de pesquisa realizada no Doutorado em Serviço Social, um mapeamento dos programas de capacitação e inserção no mercado de trabalho para a juventude latino-americana como uma das respostas construídas na Região para o atendimento das Metas de Desenvolvimento do Milênio, das quais os países foram signatários. São diversas as modalidades de programas, mas, em sua maioria, o foco está na inserção e na reinserção dos jovens no processo educacional e de qualificação profissional para seu ingresso no mercado de trabalho. $\mathrm{O}$ texto está estruturado da seguinte maneira: em um primeiro momento, desenvolve os conceitos e configurações da juventude na Região; em seguida avalia o mercado de trabalho e os programas de capacitação para essa faixa etária; depois destaca o mapeamento das experiências latino-americanas com esses programas; por fim, tece as considerações finais.

\section{Juventude latino-americana e suas configurações}

Na América Latina, no século 20, logo após a II Guerra Mundial, a juventude começou a conquistar espaços em diversas áreas: na ciência, na igreja, na sociedade, na mídia e no mercado. Um período em que a industrialização iniciada nos países latino-americanos visualizava o jovem como sujeito de direitos e de consumo (BARBIANI, 2007). "No momento em que inicia o ingresso na sociedade ampla, o jovem descortina condições e possibilidades de existência que o tornam consciente tanto das condições reais como das emergentes" (IANNI, 1968, p. 228).

A denominação dessa etapa de vida também se modificou ao longo do tempo: adolescência ${ }^{1}$, puberdade, jovem, fase adulta, jovem adulto e juventude; termos que conceituam essa fase de transição em diversas áreas: psicologia, sociologia e educação.

Antigamente, e não tanto, o trânsito da infância à idade adulta não contava com esse 'fole' temporal e anímico que hoje é a juventude, e era garantido por ritos de passagem consagrados, assim como pela incorporação precoce dos homens à vida produtiva e das mulheres à vida reprodutiva. As divisões sexual e etária do trabalho deixavam pouco espaço para ser jovem e refletir sobre a juventude (CEPAL, 2008, p. 09).

As transformações que ocorreram também se refletiram nas mudanças do papel da família a partir do período de urbanização e industrialização ${ }^{2}$. Isso influenciou diretamente a juventude, pois o aumento do número de mulheres que ingressaram no mercado de trabalho modificou as relações familiares, e houve o ingresso dos jovens em uma atividade de trabalho. Além disso, os meios de informação de massa invadiram as casas com imagens idealizadas de família e juventude.

A inserção social da juventude também se modificou ao longo dos anos. Na década de 1960, caracterizava-se pelo protagonismo em questões políticas, sociais, culturais e nos conflitos de gerações predominantes naquele período ${ }^{3}$. A partir dos anos 1970, com as mudanças econômicas e políticas, o foco da juventude também se fixou na luta pela inserção no mercado de trabalho (SPOSITO, 1997).

Torna-se relevante destacar que a idade da juventude que tem sido utilizada pela maioria dos programas de capacitação na América Latina está entre 15 e 29 anos $^{4}$, um novo recorte temporal. Porém, alguns institutos de pesquisa ainda realizam o levantamento de dados somente até os 24 anos. A juventude, nesse novo recorte geracional, também se destaca por ser um período de inserção no mercado de trabalho; são jovens que cotidianamente pressionam a economia para a criação de novos postos de trabalho, em uma contracorrente, por uma oferta mais elevada que a demanda existente: "O período da juventude prolonga-se na medida em que os processos de emancipação dos jovens são retardados por diversos motivos, como a ampliação do período de formação escolar para enfrentar as exigências do mercado de trabalho" (ABRAMOVAY; CASTRO, 2006, p. 10). Juventude também é entendida como uma categoria social com limite etário que se modificou ao longo dos anos. Entretanto, dentro da faixa etária dos 15 aos 29 anos existem outras importantes faixas, como a adolescência e a fase adulta: 
ao ser definida como categoria social, a juventude torna-se, ao mesmo tempo, uma representação sociocultural e uma situação social [...], ou seja, a juventude é uma concepção, representação ou criação simbólica, fabricada pelos grupos sociais ou pelos próprios indivíduos tidos como jovens, para significar uma série de comportamentos e atitudes a ela atribuídos. Ao mesmo tempo, é uma situação vivida em comum por certos indivíduos (GROPPO, 2000, p. 07-08).

As situações de vulnerabilidade existentes nos países latino-americanos, muitas vezes geradas pela qualidade do acesso à educação, à cultura, à renda, à saúde ou até mesmo pela falta deste, revelam o quanto os recursos são escassos, diminuindo as chances de aprendizagem ou lazer, fundamentais para o desenvolvimento da juventude. Além disso:

muito distinta é a situação de jovens urbanos e rurais, de jovens de grupos socioeconômicos carentes em relação a outros que vivem em domicílios de maior renda, de jovens de 15 a 19 anos em contraste com outros de 20 a 24 ou de 25 a 29, de jovens com pouca ou com muita educação formal, de jovens mulheres em relação a jovens homens, de jovens indígenas e afrodescendentes (CEPAL, 2008, p. 11).

As diferenças do próprio critério etário e do nível socioeconômico do jovem também se modificam de acordo com sua nacionalidade, grupo étnico, gênero ${ }^{5}$ e contexto social: "Cada juventude pode reinterpretar à sua maneira o que é 'ser jovem', contrastando não apenas em relação a crianças e adultos, mas também em relação a outras juventudes” (GROPPO, 2000, p. 15). Nessa diversidade, muitos jovens vivem em famílias em situação de pobreza ou extrema pobreza, afetando especialmente jovens de 16 a 19 anos. São distintas as oportunidades, e muitos dependem das condições familiares ${ }^{6}$, das políticas públicas ${ }^{7}$ ofertadas e da qualidade do ensino. Diante desse cenário, ao se pensar sobre a inclusão desse jovem no mercado de trabalho, após as transformações estruturais, é necessário direcionar o olhar para a educação que, historicamente, é considerada um dos principais espaços de socialização para o jovem. No entanto, embora se observe a ocorrência de aumento no número de crianças e jovens ingressando no sistema educacional a partir dos anos 1990, a educação na América Latina remete para a necessidade de se avaliar a qualidade desse ensino, além da diferenciação ao se comparar o ensino privado com o público, pois,

o aumento na oferta de vagas para o ensino público não foi devidamente acompanhado por um controle da qualidade da educação que se oferecia. Como resultado, passou a ser ineficiente diante da nova realidade, provocando um aumento crescente nos níveis de repetência e também nas avaliações negativas sobre os conhecimentos adquiridos (ABRAMOVAY et al., 2002, p. 44).

Outro agravante que configura uma realidade no cotidiano de muitos jovens seria o fato de que muitos deles abandonam os estudos diante da falta de perspectivas de trabalho ou até mesmo para ingressarem nesse mercado, "comprometendo muitas vezes seu processo de formação e capacitação profissional” (ABRAMOVAY et al., 2002, p. 45). Há casos, inclusive, de jovens que não chegam a se alfabetizar. Os estudos da Comissão Econômica para a América Latina (CEPAL) e da Organização das Nações Unidas para a Educação, a Ciência e a Cultura (UNESCO) indicam a necessidade de investir na educação, em sua universalidade visando desenvolver capacidades e acesso a oportunidades. Porém, embora se observe um avanço na educação em termos de acesso, acessibilidade, aceitabilidade e aumento de investimento público ${ }^{8}$, a qualidade desse ensino muitas vezes não é avaliada, o que compromete os resultados. Além disso, é necessário avaliar os seguintes aspectos: quais oportunidades estão disponíveis para os jovens? Quais capacidades o mercado vem exigindo? A realidade de vida de jovens em condições socioeconômicas menos favoráveis, se comparada com a dos jovens que vivem em famílias de classe média e média alta, se diferencia em muitas situações, sendo a educação a relação existente entre educação e mercado de trabalho vem se modificando motivada pelas transformações econômicas, criando novas e complexas demandas de qualificação e, além disso, alterando a utilização da mão de obra já existente.

formal uma das principais: para alguns existe a possibilidade de investir nos estudos e adiar o ingresso no mercado de trabalho; para outros, deixar o estudo é o foco principal de vida. 
Conforme já se mencionou, a relação existente entre educação e mercado de trabalho vem se modificando motivada pelas transformações econômicas, criando novas e complexas demandas de qualificação e, além disso, alterando a utilização da mão de obra já existente. Assim, no próximo item discorre-se sobre esse novo mercado de trabalho e sua relação com os programas de capacitação para a juventude, abrangendo-se dois enfoques conceituais para análise: mercado de trabalho e programas de capacitação para a juventude, ou seja, as modificações que esse mercado vivenciou, principalmente a partir dos anos 1980, e os programas de capacitação para a juventude a partir dos anos 1990 na América Latina.

\section{Mercado de trabalho para a juventude na América Latina}

Para se refletir sobre o mercado de trabalho e os programas de capacitação voltados à juventude é necessário compreendê-los no âmbito cultural, político, social e econômico em que se inserem, com suas particularidades locais e territoriais. Para tanto, passa-se a contextualizar o mercado de trabalho disponível para a juventude após os anos de 1990, principalmente na sequência das reformas estruturais. As primeiras propostas dos programas para a juventude surgiram através dos governos ibero-americanos ${ }^{9}$, na década de 1990, quando se iniciou a criação de leis, a elaboração e execução de planos e programas para a juventude e, também, as pesquisas sobre o jovem ${ }^{10}$. Porém, as Nações Unidas já haviam declarado o ano de 1985 como o Ano Internacional da Juventude, com a aprovação de diretrizes que deveriam orientar futuras ações. Ademais, em 1995 a Assembleia Geral aprovou o Programa de Ação Mundial para os jovens até o ano 2000, em 1998 foi aprovada a Declaração de Lisboa sobre políticas e programas voltados à juventude e em 2008 foi declarado o ano Ibero-Americano da Juventude.

Nas ações visando garantir direitos aos jovens e na Convenção Ibero-Americana de Direitos dos Jovens (OIJ, 2008), destaca-se o quanto os governos devem se comprometer a adotar medidas necessárias para garantir aos jovens, dentre vários compromissos, o direito à capacitação para acessar melhores empregos e fomentar políticas de estímulo às empresas como forma de inserção. A realidade a ser enfrentada pela juventude em relação ao emprego, principalmente a partir dos anos de 1990, tornou-se preocupação mundial. A criação de tantas leis e programas surgiu da realidade observada na década de 1990 nos países latino-americanos, quando os ajustes estruturais foram implantados na maioria deles. Mas a preocupação com a capacitação para o trabalho também consta nos Objetivos e Metas de Desenvolvimento do Milênio ${ }^{11}$, pois as mudanças econômicas, políticas e tecnológicas e o crescimento econômico entre baixo e moderado na maioria dos países geraram efeitos adicionais na composição do emprego (WELLER, 2006).

Para muitos jovens o emprego pode ser considerado o principal acesso à inclusão social, possibilitando-lhes manter as necessidades básicas e o acesso à proteção social, além de desenvolver o sentimento de pertencimento. Para a juventude, ingressar no mercado de trabalho pode ser uma forma de demarcar as mudanças que essa fase determina. Em realidade, trata-se de um período de vigorosas mudanças comportamentais que podem ser entendidas como contradições produzidas pelo próprio capital, considerando-se que, no final do século 20, surge um discurso sobre o desenvolvimento tecnológico e suas vantagens para o ingresso no mercado de trabalho. No entanto, poucos conseguem acessar tal progresso, pois "a sociedade que exclui é a mesma sociedade que inclui, integra e cria formas também desumanas de participação, na medida em que delas faz condição de privilégios e não de direitos" (MARTINS, 2002, p. 11). As modificações decorrentes da revolução tecnológica atingem vários níveis: métodos de produção, organização das fábricas, das empresas, dos serviços e a própria política de financiamento dos governos, portanto aquele que se encontra fora deste acesso também sofre perdas e poderá ficar a um passo do abismo (MARTINS, 2002). Conforme Antunes (2005, p. 43): "as empresas, na competitividade travada entre elas, visando reduzir o tempo entre produção e consumo, incentivam ao limite essa tendência restritiva do valor de uso das mercadorias". Tantas modificações estruturais agravaram o ingresso do jovem no mercado de trabalho na metade dos anos 1990, com maior porcentagem em alguns países na década de 2000, observando-se, além disso, "menor capacidade de absorção do setor informal, o que se traduziu em altas e persistentes taxas de desemprego em alguns países, apesar de anos de importante crescimento econômico" (CEPAL, 2008, p. 170), aumentando o percentual de jovens em setores de baixa produtividade. Os dados da América Latina e do Caribe indicam que há cerca de 106 milhões de jovens, entre 15 e 24 anos, e que destes, 58 milhões contabilizam a força de trabalho, quase 10 milhões estão desempregados e 30 milhões trabalham na economia informal. Outros 48 milhões são considerados inativos, pois não trabalham e não buscam trabalho (CEPAL, 2008). Metade dos jovens latino-americanos está empregada, mas em sua maioria inseridos em atividades informais, com contratos sem garantias de proteção social, terceirizados, subcontratados, sendo este o único percentual que demonstra crescimento, "isso porque o capital necessita cada vez menos do trabalho estável e cada vez mais de trabalho part-time, terceirizado, que se encontra em enorme crescimento no mundo produtivo industrial e de serviços" (ANTUNES, 2005, p. 42). 
Tabela 1: América Latina (17 países): indicadores de trabalho para jovens de 15 a 29 anos de idade, em torno dos 1990, 2000 e 2005 (em médias simples)

\begin{tabular}{|c|c|c|c|c|c|c|c|c|c|}
\hline & \multicolumn{3}{|c|}{ Total } & \multicolumn{3}{|c|}{ Mulheres } & \multicolumn{3}{|c|}{ Homens } \\
\hline & 1990 & 2000 & 2005 & 1990 & 2000 & 2005 & 1990 & 2000 & 2005 \\
\hline Taxa de participação & 56,6 & 58,1 & 57,8 & 74,7 & 71,6 & 70,7 & 39,7 & 45,1 & 45,4 \\
\hline Taxa de ocupação & 49,3 & 49,3 & 50,6 & 66,5 & 62,8 & 63,6 & 33,1 & 36,2 & 38,0 \\
\hline Taxa de desemprego & 12,8 & 16,1 & 12,5 & 10,9 & 13,6 & 10,2 & 15,9 & 20,0 & 15,8 \\
\hline $\begin{array}{l}\text { Porcentagem de desempregado que } \\
\text { busca há um ano ou mais }\end{array}$ & 17,8 & 15,8 & 10,9 & 17,2 & 15,5 & 9,7 & 18,2 & 16,1 & 12,0 \\
\hline $\begin{array}{l}\text { Taxa de desemprego relativa à taxa } \\
\text { de desemprego adulto }\end{array}$ & 2,68 & 2,30 & 2,73 & 2,54 & 2,25 & 2,63 & 2,80 & 2,36 & 2,89 \\
\hline Porcentagem de estudantes & 22,0 & 23,9 & 25,4 & 21,6 & 23,0 & 24,1 & 22,8 & 24,9 & 26,7 \\
\hline $\begin{array}{l}\text { Porcentagem de inativos que não es- } \\
\text { tudam nem se dedicam a afazeres do- } \\
\text { mésticos }\end{array}$ & 4,4 & 3,7 & 4,1 & 4,8 & 3,9 & 4,4 & 3,7 & 3,5 & 3,8 \\
\hline $\begin{array}{l}\text { Porcentagem de ocupados em seto- } \\
\text { res de baixa produtividade }\end{array}$ & 48,7 & 50,7 & 45,7 & 47,0 & 48,8 & 43,2 & 51,1 & 53,2 & 49,0 \\
\hline
\end{tabular}

\section{Fonte: CEPAL(2008).}

Embora as taxas de desemprego tenham demonstrado pequena diminuição entre os anos de 2004 e 2007 na América Latina, o tipo de ingresso no mercado de trabalho não se modificou, conforme os dados da Tabela 1. Quase a metade do percentual de jovens que se inseriu no mercado de trabalho, a partir dos anos 1990, o fez em setores de baixa produtividade, ou seja, em atividades instáveis, burocráticas, pouco qualificadas, sem conteúdo e questionamento, rotinizadas e com ausência de perspectiva profissional, mas as realizam diante da falta de alternativas e emprego no mercado formal ${ }^{12}$ (BAJOIT; FRANSSEN, 2007). A falta de oportunidades para a juventude, no final do século 20 e início do século 21 , fez aumentar a desigualdade social, a competição e o individualismo que caracteriza este século, limitando-a, muitas vezes, a sair de uma condição de subalternidade. Em sua maioria, os jovens recebem uma educação precária, que não corresponde às necessidades do mercado de trabalho, contribuindo para inseri-los no mercado informal. Para a juventude, independente das condições econômicas, a educação é uma forma de inclusão no mercado de trabalho. No entanto, muitos jovens, com condições de se qualificarem, disputam vagas que não necessitariam de tanta qualificação, e os "realmente não qualificados correm o risco de não ter nenhuma alternativa para o desemprego, visto que os postos que poderiam ocupar estão tomados por outros mais qualificados que eles" (CASTEL, 2008, p. 520). Ao mesmo tempo, a juventude vivencia dois tipos de mercado de trabalho: o mercado primário, mais restrito, formado por jovens com relações mais estáveis, relações formais de trabalho, salários bem pagos, com a qualificação exigida, disponibilidade para viagens, instrumentos de trabalho necessários (notebook, smartphones), flexibilidade no horário e disponibilidade 24 horas por dia; e o mercado secundário, formado, em sua maioria, por trabalhadores menos qualificados, com relações de trabalho precarizadas, de exploração, com uma carga horária formal de 10, 12 ou 14 horas, sem direitos garantidos, e "submetidos às flutuações da demanda" (CASTEL, 2008, p. 524). Esses dois tipos de relações de trabalho, embora tão diferenciados, estão submetidos às demandas do mercado e, mesmo não concorrendo diretamente entre si, em momentos de crise poderão vir a concorrer, quando o percentual de jovens que se qualificou em nível terciário assume vagas para as quais a exigência escolar é mínima diante de seus anos de estudo.

Os dados da Organização Internacional do Trabalho (OIT) indicam que, mundialmente, "uma em cada cinco pessoas com idade entre 15 e 24 anos está desempregada, ou seja, 88 milhões de jovens, que representam mais de $40 \%$ do total de desempregados. Destes, $85 \%$ encontram-se em países em desenvolvimento" (OIT, 2010), havendo a perspectiva de 660 milhões de jovens ingressarem no mercado de trabalho nos próximos dez anos. Com as taxas de desemprego em alta na maioria dos países latino-americanos, o ingresso no mundo do trabalho formal para a juventude se distancia. Almejá-lo, qualificar-se para disputar uma vaga não será suficiente diante da realidade de desempregados. E o trabalho, fonte de sobrevivência, de criação, perde 
suas características diante da demanda ofertada. A satisfação das necessidades humanas de sobrevivência muitas vezes submete os sujeitos a situações de humilhação e exploração da mão de obra. O emprego formal, principalmente, que sempre assumiu sentido de pertencimento para a juventude ao ingressar no mercado de trabalho, dá lugar à sensação de não pertencimento, que se torna parte do cotidiano de suas vidas após as mudanças estruturais ao longo do processo de reestruturação.

Essas realidades desafiam cotidianamente os governos no desenvolvimento de políticas e programas para a juventude. Como enfrentar um mercado de trabalho restrito a poucas vagas de trabalho e às condições do mercado? Como estimular o jovem a ingressar em programas de capacitação diante da falta de emprego formal? Quais os objetivos desses programas? Não seriam novas estratégias do capital? Esses questionamentos encaminham a discussão para o próximo item, no qual se apresenta um mapeamento dos programas de capacitação para a juventude criados pelos governos latino-americanos a partir de 1990.

\section{Programas para a juventude: mapeamento das experiências latino-americanas}

Os programas de capacitação para a juventude, iniciados na década de 1990, deveriam ocupar uma posição estratégica para a inserção do jovem no mercado de trabalho, principalmente após a proliferação do desemprego estrutural na América Latina. Embora os programas se assemelhem quanto ao público-alvo de suas ações e em alguns objetivos, existem particularidades significativas diante da trajetória de cada país. A intenção, aqui, é sintetizar as principais características dos programas governamentais, seus objetivos e público-alvo, a fim de construir um panorama dos programas de capacitação para a juventude em execução na América Latina a partir de 1990. A pesquisa utilizou-se de amostra representativa, uma amostragem por intencionalidade, composta pelos países Argentina e Brasil, objetivando realizar um estudo comparativo dos programas de capacitação para a juventude como resposta ao desemprego estrutural. Os critérios para a escolha dos países foram: o percentual da população com idade entre 15 e 29 anos, sendo esta a idade do público-alvo dos programas desses países, a semelhança entre os percentuais de investimento na educação para os jovens, as altas taxas de desemprego, principalmente na década de 1990, e a semelhança nos objetivos dos programas, ou seja, incentivos à capacitação dos jovens como forma de inserção ou reinserção no trabalho. $\mathrm{O}$ estudo teve como base de trabalho de investigação relatórios e documentos elaborados por organismos oficiais e reconhecidos pela OIT, pela Organização Ibero-Americana da Juventude (OIJ), pela UNESCO e pela CEPAL. Tais programas surgiram após várias ações dos governos Ibero-Americanos ${ }^{13} \mathrm{e}$ a publicação dos Objetivos de Desenvolvimento do Milênio ${ }^{14}$, constituídos por uma agenda que visava ao desenvolvimento mundial, compondo um conjunto de oito objetivos e dezoito metas, tendo 25 anos de prazo para seu cumprimento, entre 1990 e 2015. Os oito objetivos são: erradicar a extrema pobreza e a fome; tornar o ensino básico universal; promover igualdade; reduzir a mortalidade infantil; melhorar a saúde materna; combater o HIV/ AIDS, a malária e outras doenças; garantir a sustentabilidade universal; e estabelecer parceria mundial para o desenvolvimento. Além disso, uma das metas (16) seria, em cooperação com os países em desenvolvimento, elaborar e executar estratégias que proporcionem aos jovens um trabalho digno e produtivo (OIT, 2010).

Os dados pesquisados no site do Projeto de Promoção do Emprego de Jovens na América Latina (PREJAL) (OIT, 2010) ${ }^{15}$ indicam que 13 países da América Latina e Caribe executavam programas de capacitação para a juventude, com o objetivo de capacitação e inserção no mercado de trabalho, entre 1990 e 2010. São eles: Argentina, Brasil, Bolívia, Chile, Colômbia, Costa Rica, El Salvador, Honduras, México, Paraguai, Peru, República Dominicana e Uruguai, com um total de 42 programas governamentais ${ }^{16}$.

Na década de 1990 foram implementados sete programas em cinco países: Chile, México, Peru, República Dominicana e Uruguai e, após o ano 2000, esse número aumentou para 34 programas em mais oito países. Um dos fatores que também incidiu no aumento dos programas foi o PREJAL/OIT, que até 2010 estava sendo executado na Argentina, Brasil, Chile, Colômbia, Honduras, Peru, República Dominicana e México, formando uma associação entre setores públicos e privados.

No mapeamento realizado das experiências nacionais latino-americanas identificam-se algumas características, sendo que o objetivo geral de grande parte dos programas volta-se para a inserção do jovem no mercado de trabalho através da capacitação e/ou qualificação, conforme orientação dos organismos envolvidos. A análise documental realizada permite indicar, de forma geral, os principais objetivos dos programas de capacitação para a juventude, que são: oportunizar a inclusão social; finalizar a escolaridade; incitar experiência de práticas qualificantes; facilitar a transição escola-trabalho; dar orientações sobre trabalho; melhorar as condições socioeconômicas; melhorar as competências e habilidades dos jovens; reduzir a desigualdade entre os jovens através da educação, promover qualificação e ação comunitária; promover inclusão em programas de capacitação diversos; promover e apoiar a contratação de jovens na condição de aprendizes; incitar a 
inclusão em vagas de estágio; auxiliar na elaboração de um plano de ação de empregabilidade; oportunizar a finalização do ensino primário ou fundamental; promover capacitação com foco no meio ambiente.

Dos 42 programas mapeados, 33 indicam a idade dos jovens a partir dos 14 anos, mas em sua maioria consta a partir dos 15 anos até o máximo de 35 anos, o que já incluiria a idade adulta (apenas um programa). $\mathrm{O}$ restante divide-se, principalmente, até o máximo de 24, 25, 28 ou 29 anos. Embora todos indiquem como público-alvo o jovem, alguns programas especificam, além da idade, as condições socioeconômicas, ou seja, jovens de famílias pobres, vulneráveis, e, além destes, os jovens do meio rural, ou da cidade, jovens migrantes, jovens que prestam serviço militar, jovens infratores, jovens que não finalizaram o ensino fundamental ou médio, jovens que não estudam e não trabalham, mulheres jovens ou jovens pertencentes a programas sociais de transferência de renda, nesse caso, principalmente o adolescente. Destaca-se que, dentre as características dos programas, muitos objetivam fomentar a inclusão dos jovens no mercado de trabalho através do repasse de verbas às empresas privadas, como uma bonificação para o contratante, além de repasses de bolsas e linhas de crédito diretamente aos jovens ${ }^{17}$. O Ministério do Trabalho, Emprego e Seguridade Social se destaca, na maioria dos programas, por formular, elaborar e fomentar os planos e projetos voltados à capacitação e à inserção da juventude no mercado de trabalho e, dentre os 13 países pesquisados, o Ministério do Trabalho é o responsável pela execução da maioria dos programas. Nota-se que há uma diversidade de coordenações e fragmentação de ações, fragilizando a proposta de uma política para a juventude, contrariando a indicação da Convenção Ibero-americana da Juventude, de que todos os governos sejam responsáveis pela coordenação e avaliação das políticas para os jovens, que promovam todas as medidas legais e fomentem a organização e consolidação das estruturas para a juventude (OIT, 2010).

As leis gerais para a juventude surgiram a partir dos anos 1990 em alguns países. Em 2007 a Argentina criou, através da Lei n. 26.227, o Conselho Federal de Juventude visando a participação na concepção e coordenação Interjurisdicional; o Brasil, em 2005, criou a Lei n. 11.129 (modificando as leis de 2002 e 2003), instituindo o Programa Nacional de Inclusão de Jovens, e criou o Conselho Nacional da Juventude e a Secretaria Nacional de Juventude; o Chile foi o pioneiro, criando, em 1991, a Lei n. 19.042 que instituiu o Instituto Nacional de Juventude, encarregado de colaborar com o poder executivo (OIT, 2010). Por sua vez, a Colômbia, em 1997, criou a Lei da Juventude n. 375, estabelecendo o marco institucional e orientador das políticas, planos e programas por parte do Estado e da sociedade civil; a Costa Rica, em 2002, criou a Lei Geral para Pessoas Jovens, n. 8261, com o objetivo de elaborar, promover, coordenar e executar políticas públicas voltadas aos jovens, e o Conselho Nacional de Políticas Públicas para o jovem; o Equador, em 2001, criou a Lei da Juventude, $\mathrm{n}^{\circ}$ 2001-49, a qual reconhece a particularidade dos jovens, a fim de promover o efetivo gozo e exercício de seus direitos e garantir o cumprimento dos deveres e obrigações; Honduras, em 2005, criou a Lei Marco para o Desenvolvimento Integral da Juventude, Decreto n. 260, e o Instituto Nacional da Juventude; o México, em 1999, criou a Lei do Instituto Mexicano da Juventude como um organismo público descentralizado (OIT, 2010). A Nicarágua, em 2001, criou a Lei de Promoção do Desenvolvimento Integral da Juventude, n. 392, com o objetivo de promover o desenvolvimento humano dos jovens, garantindo o exercício de seus direitos e obrigações, estabelecer políticas institucionais e mobilizar recursos do Estado e sociedade civil; o Paraguai, em 2009, criou o anteprojeto da Lei Nacional de Juventude; o Peru criou, em 2002, a Lei do Conselho Nacional de Juventude, n. 27802, estabelecendo o marco normativo e institucional que orienta as ações do Estado e sociedade civil; a República Dominicana criou, em 2000, a Lei Geral da Juventude, n. 49-2000, para instaurar o marco jurídico, político e institucional que orienta o Estado e a sociedade na elaboração e implementação das políticas (OIT, 2010).

Maioria destas leis incentiva a criação de programas e projetos para serem executados pelo Estado e sociedade civil, geralmente com recursos internacionais. Ao realizar o mapeamento dos programas de capacitação e inserção ao trabalho através do site do PREJAL (OIT, 2010), identificou-se um número expressivo de programas nesse contexto. A título de exemplo, citam-se: Argentina (13); Chile (11); Honduras (8); Brasil (6); México (5) e outros países com número menor desse tipo de programa.

\section{Considerações finais}

Os processos de urbanização e industrialização vivenciados na América Latina acarretaram, ao longo dos anos, modificações econômicas, políticas e sociais que desencadearam a (re)produção da desigualdade social na região, afetando diretamente a juventude. E a nova lógica do mercado de trabalho para a juventude faz com que os jovens concorram de modo desigual entre si, pois as exigências de qualificação vão além das necessidades reais. O capital impõe um perfil para o jovem que envolve características nunca antes exigidas. A resposta dos países da América Latina, diante do contingente de jovens fora do mercado de trabalho, se 
constitui na criação de programas de capacitação para a juventude a partir da inserção em processos educacionais e de qualificação para o trabalho. Esses programas surgiram após a publicação dos objetivos das Metas do Desenvolvimento do Milênio. Ao se realizar o mapeamento das experiências latino-americanas para a juventude, observou-se o quanto tais propostas se assemelham em diversos aspectos, mas também se diferenciam em aspectos importantes que poderiam auxiliar a avaliação da eficácia dos projetos, como: a obrigatoriedade da criação de leis para a juventude, o tempo de permanência nos programas, o órgão responsável pela execução e, principalmente, a idade para participar do programa, a qual varia conforme o país.

Referente ao período estudado constata-se que os programas foram executados por instituições privadas, em sua maioria com recursos internacionais ou repasse do fundo público. Essa realidade exemplifica as mudanças no papel do Estado, principalmente a partir da década de 1990, quando ocorreu um crescimento significativo de parcerias com a sociedade civil na execução das políticas públicas, comprometendo ainda mais a possibilidade de homogeneidade dos programas. Uma contradição evidenciada neste estudo foi a relação com o público-alvo dos programas. Em sua maioria são jovens em situação de vulnerabilidade, mas, ao mesmo tempo, nega-se tal situação, oferecendo-lhes cursos que não respondem a sua demanda imediata, e, por vezes, culpando-os pelo fracasso e pelas dificuldades de inserção no mercado de trabalho. Observa-se, portanto, um mercado que não oferece alternativas de trabalho possíveis, a criação de novas vagas e melhores remunerações, criando programas desvinculados da realidade cotidiana desses jovens, respondendo apenas a uma necessidade do capital.

Os programas de capacitação para a juventude são desafios para os profissionais, tanto na formulação quanto na execução dessas políticas. Assim, desvendar as especificidades culturais e sociais desses jovens poderá auxiliar na compreensão dos processos desses sujeitos com os quais muito se intervém no cotidiano de trabalho.

\section{Referências}

ABRAMOVAY, M.; CASTRO, M. G. (Coord.). Juventude, juventudes: o que une e o que separa. Brasília, DF: UNESCO, 2006. et. al. Juventude, violência e vulnerabilidade social na América Latina: desafios para políticas públicas. Brasília, DF: UNESCO, BID, 2002.

NTUNES, R. O caracol e sua concha: ensaios sobre a nova morfologia do trabalho. São Paulo: Boitempo, 2005.

BAJOIT, G.; FRANSSEN, A. O trabalho, busca de sentido. In: SPÓSITO, Marília et. al. (Org.). Juventude e contemporaneidade. Brasília, DF: UNESCO, MEC, ANPEd, 2007.

BARBIANI, R. Mapeando o discurso teórico latino-americano sobre juventude (s): a unidade na diversidade. Revista Virtual Textos \& Contextos, v. 6, n. 1, p. 138-153. jan./jun. 2007.

CASTEL, R. As metamorfoses da questão social: uma crônica do salário. Tradução Iraci D. Poleti. Petrópolis: Vozes, 2008.

COMISSÃO ECONÔMICA PARA A AMÉRICA LATINA - CEPAL. Juventude e coesão social na Iberoamérica: um modelo a ser construído. Santiago: CEPAL, 2008.

GROPPO, L. A. Juventude: ensaios sobre sociologia e história das juventudes modernas. Rio de Janeiro: DIFEL, 2000.

IANNI, O. O Jovem Radical. In: BRITTO, S. de (Org.). Sociologia da juventude: a vida coletiva juvenil. Rio de Janeiro: Zahar, 1968. INSTITUTO BRASILEIRO DE GEOGRAFIA E ESTATÍSTICA - IBGE. População jovem no Brasil. Rio de Janeiro: IBGE, 1999. Disponível em: <http://www.ibge.gov.br/home/ estatistica/populacao/populacao_jovem_brasil/comentario1.pdf >. Acesso em: 30 nov. 2009.

. Censo Demográfico 2000. Rio de Janeiro: IBGE, 2000. Disponível em: <http://www.ibge.gov.br〉. Acesso em: 30 nov. 2009. MARTINS, J. S. A sociedade vista do abismo: um estudo sobre a exclusão social, pobreza e classes sociais. Petrópolis: Vozes, 2002. ORGANIZAÇÃO INTERNACIONAL DO TRABALHO - OIT. Trabajo decente y juventude em America Latina: avances y propuestas. Lima: OIT, 2010. Disponível em: 〈http://prejal.lim.ilo.org/prejal/docs/DOC_REUREG_FINAL.pdf〉. Acesso em: 20 jul. 2012.

ORGANIZACIÓN IBEROAMERICANA DE JUVENTUD - OIJ. Convención Iberoamericana de Derechos de los Jóvenes. Madrid: OIJ, 2008. Disponível em: 〈http://www.unicef.org/lac/CIDJpdf(3).pdf〉. Acesso em: 20 nov. 2012.

SPOSITO, M. P. Estudos sobre juventude em educação. Revista Brasileira de Educação, n. 5, p. 37-52, mai./ ago. 1997.

WELLER, J. (Ed.). Los jóvenes y el empleo en América Latina: desafíos y perspectivas ante el nuevo escenario laboral. Colombia: CEPAL, 2006.

\section{Notas}

1 “Adolescênciaé uma fase de preparação psicossocial para a idade adultae a sociedade, fase da definição de uma identidade e de uma individualidade [...]. É um estágio em que os desenvolvimentos pré-genitais, genitais e psicológicos da infância encontram padrões culturais de um meio social no qual o indivíduo terá de se realizar e continuar a evolução" (GROPPO, 2000, p. 61). Uma realidade muitas vezes difícil de encontrar, diante da realidade social dos países. Em vários casos, algumas etapas não são vivenciadas. 
2 A partir deste período de industrialização, observa-se uma cronologização da vida, na tentativa de delimitar os estágios/fases que se vivencia.

3 “A juventude típica do século 20, a juventude 'rebelde-sem-causa', radical ou delinquenteé, primordialmente, uma imagem baseada no jovem das chamadas 'novas classes médias'. [...] São outras juventudes que construíram para si representações e relações sociais concretas distintas, em diversos graus, do padrão considerado ideal ou típico da juventude em sua época" (GROPPO, 2000, p. 16).

4 Como exemplo, a partir da série dos Censos Demográficos brasileirosé possível avaliar a evolução do contingente de 15 a 24 anos de idade. Embora os efetivos absolutos apresentem uma tendência de crescimento, estes experimentam um paulatino processo de desaceleração a partir da década de 1970. Em 1940, eram 8,2 milhões de jovens neste grupo etário e, 30 anos depois, estes jovens e adultos jovens já somavam 18,5 milhões. Em anos mais recentes, 1991 e 1996, os respectivos censos populacionais enumeraram 28,6 e 31,1 milhões de pessoas de 15 a 24 anos de idade. (IBGE, 1999).

5 Não se pretende ter como foco a questão de gênero ao discutir os programas de capacitação voltados à juventude e sua inserção no mercado de trabalho, mas torna-se relevante destacar que a juventude vivida pela mulher difere da juventude vivida pelo homem em vários aspectos: educação, inserção ao trabalho, sexualidade, entre outros.

6 Além da situação socioeconômica da família, esse núcleo vem se modificando, definindo papéis e alterando a composição de seus membros por idade, pelo número de filhos; socializam-se as normas e a forma de legitimar a autoridade (CEPAL, 2008): "Estas mudanças favorecem o surgimento de novas formas de organização familiar na América Latina: famílias monoparentais, lares com pessoas sós, uniões de fato, jovens que não constituem famílias, famílias recompostas ou complexas, famílias a distância e outras" (CEPAL, 2008, p. 257). Mas, em muitos casos, o chamado lar não se apresenta como o local mais seguro ao vivenciar situações de violência, expulsando o jovem para uma realidade muitas vezes de risco.

7 As políticas públicas ofertadas para os jovens na América Latina são, em sua maioria, elaboradas para uma parcela destes, principalmente aqueles considerados em vulnerabilidade ou risco social (ABRAMOVAY; CASTRO, 2006).

8 O percentual de investimento público na educação entre os países latino-americanos se diferencia entre si e entre os níveis educativos (primário, secundário, terciário): "Há países onde o gasto público anual por estudante em qualquer dos níveis não supera 500 dólares (Bolívia, Colômbia, El Salvador, Guatemala, Nicarágua, República Dominicana, Paraguai e Peru); na Guatemala e Nicarágua estes valores não superam os 100 dólares anuais. Num conjunto amplo de países (Argentina, Brasil, Chile, Costa Rica, Cuba, México, Panamáe Uruguai) se destinam recursos significativos que variam desde 500 a 2.500 dólares, dependendo do nível educativo, com bastante heterogeneidade entre si e em relação à concentração de recursos por estudante nos diversos níveis" (CEPAL, 2008, p. 119).

9 Compõem os países da América Latina e três países da Península Ibérica (Portugal, Espanha e Andorra).

10 "Um número crescente de países está ratificando a Convenção Ibero-Americana de Direitos dos Jovens (CIDJ). Essa Convenção, que entrou em vigor em $1^{\circ}$ de março de 2008 e é o único tratado internacional do mundo que reconhece a juventude como sujeito específico de direito e ator estratégico do desenvolvimento, foi elaborada e promovida pela OIJ" (CEPAL, 2008, p. 26). Países que ratificaram a Convenção: República Dominicana, Equador, Costa Rica, Honduras, Espanha, Uruguai e Bolívia. Países que assinaram e estão em processo de ratificação: Cuba, Guatemala, México, Panamá, Nicarágua, Paraguai, Peru, Portugal e Venezuela. Países que ainda não assinaram: Argentina, Colômbia, El Salvador, Chile, Andorra e Brasil (OIJ, 2008).

11 O oitavo objetivo indica fomentar uma associação mundial para o desenvolvimento e especificamente a meta 16 cita, "em cooperação com os países em desenvolvimento, elaborar e aplicar estratégias que proporcionem aos jovens um trabalho digno e produtivo". Além disso, na 93a Conferência Internacional do Trabalho em 2005, a Organização Internacional do Trabalho (OIT) assumiu o compromisso de buscar o trabalho decente para os jovens como um elemento crucial para avançar na erradicação da pobreza e para alcançar o desenvolvimento sustentável (OIT, 2010).

12 Especificamente no Brasil, os dados do IBGE (2000) apontam 34.092.224 de jovens com idade entre 15 e 24 anos, algo significativo mesmo diante do envelhecimento da população brasileira e da desaceleração do contingente de jovens, pois com a falta de perspectiva no mercado de trabalho é necessário repensar como inseri-los, e convive-se com o desemprego de 3,5 milhões de pessoas com idade entre 16 e 24 anos, em torno de $45 \%$ da força de trabalho nacional (OIT, 2010).

13 Em 2008 se realizou o marco da Cúpula de Presidentes e Chefes de Estado e de Governos Ibero-americanos, e o I Foro Ibero-americano de Ministras e Ministros do Trabalho, com o lema "Juventude, trabalho decente e desenvolvimento com democracia", onde se aprovou a Declaração de Sonsonate e foram acordadas diferentes medidas encaminhadas a promover o trabalho decente para os jovens dos países ibero-americanos (OIT, 2010). Em maio de 2010, Salvador, Bahia, ocorreu a Pré-Conferência das Américas que precede a Conferência Mundial da Juventude, que se realizou no México em agosto de 2010. No Brasil, em Salvador, se escreveu La Carta de Bahia, a qual reconhece o desafio que significa combater a pobreza e a desigualdade, além de melhorar a formação e o emprego para os jovens. Entre os principais pontos que foram acordados entre os participantes está o esforço de eliminar a discriminação e a desigualdade, promover o trabalho decente e a participação juvenil na elaboração de políticas públicas, buscar a igualdade de gênero, étnica e racial, além de indicar que o acesso à educação seja universal e de qualidade (OIT, 2010).

14 Em setembro de 2000, 189 chefes de Estado e de Governo reuniram-se na sede das Nações Unidas em Nova Iorque para firmar a Declaração do Milênio, comprometendo-se a trabalhar juntos para a erradicação da pobreza extrema mundial. Com base neste acordo surgiram os oito Objetivos de Desenvolvimento do Milênio (OIT, 2010).

15 OPREJAL, da OIT, objetiva promover o trabalho decente para os jovens através da sensibilização e da inclusão do emprego juvenil nas políticas e programas públicos. Este projeto se inscreve dentro das iniciativas da Rede de Emprego Juvenil, impulsionada pela Secretaria Geral da Organização das Nações Unidas (ONU) e pelo Programa Global de Emprego da OIT, e tem o respaldo do governo espanhol e de um grupo de empresas deste país desde 2009. São três eixos de ação: político, técnico e prática empresarial (OIT, 2010). 
16 Embora a Nicarágua esteja sendo citada no quadro, não será contabilizada no total de programas e países, pois o programa finalizou em 2009.

17 As linhas de crédito são específicas para jovens do meio rural como um incentivo para a permanência deles no meio rural.

\section{Aline Espindola Dornelles}

alined@fasc.prefpoa.com.br

Doutora em Serviço Social pela PUCRS.

Assistente Social da Coordenação de Gestão de Recursos Humanos da Fundação de Assistência Social e Cidadania (FASC)

\section{Carlos Nelson dos Reis}

cnelson@pucrs.br

Doutorado em Política Econômica pela Universidade Estadual de Campinas

Professor Titular da Pontifícia Universidade Católica do Rio Grande do Sul (PUC-RS)

\section{Vanessa Maria Panozzo}

vanessa.panozzo@ufrgs.br

Doutorado em Serviço Social pela Pontifícia Universidade Católica do Rio Grande do Sul (PUCRS)

Professora e Pesquisadora do Departamento de Serviço Social Universidade Federal do Rio Grande do Sul (UFRGS)

\section{FASC}

Avenida Ipiranga, 310, Praia de Belas

Porto Alegre - Rio Grande do Sul - Brasil

CEP: 90160-090

\section{PUC-RS}

Avenida Ipiranga, 6681, Partenon

Porto Alegre - Rio Grande do Sul - Brasil

CEP: 90619-900

\section{UFRGS}

Departamento de Serviço Social - Instituto de Psicologia

Rua Ramiro Barcellos, 2777, Sala 318, Santa Cecília

Porto Alegre - Rio Grande do Sul - Brasil

CEP: 90035-003 